\title{
Leakage-free, guidance of light in hollow core optical fibers
}

\author{
Libori, Stig E. Barkou; Broeng, Jes; Bjarklev, Anders Overgaard
}

Published in:

Lasers and Electro-Optics

Link to article, DOI:

10.1109/CLEO.2000.907061

Publication date:

2000

Document Version

Publisher's PDF, also known as Version of record

Link back to DTU Orbit

Citation (APA):

Libori, S. E. B., Broeng, J., \& Bjarklev, A. O. (2000). Leakage-free, guidance of light in hollow core optical fibers. In Lasers and Electro-Optics (pp. 318-319). https://doi.org/10.1109/CLEO.2000.907061

\section{General rights}

Copyright and moral rights for the publications made accessible in the public portal are retained by the authors and/or other copyright owners and it is a condition of accessing publications that users recognise and abide by the legal requirements associated with these rights.

- Users may download and print one copy of any publication from the public portal for the purpose of private study or research.

- You may not further distribute the material or use it for any profit-making activity or commercial gain

- You may freely distribute the URL identifying the publication in the public portal

If you believe that this document breaches copyright please contact us providing details, and we will remove access to the work immediately and investigate your claim 


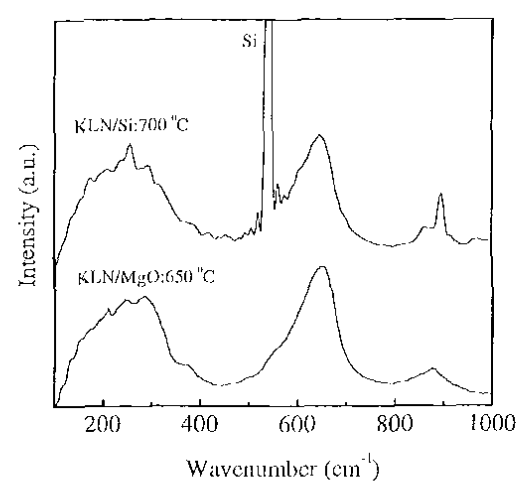

CWK39 lïg. 2. Raman spectra of KIN films.

measured and the result showed that the film is highly transparent in the visible-near infrared spectral range, which is very important for the generation of blue-green lasers via $\mathrm{SHG}$ through near infrared laser diode pumping. The transmission rapidly decreases when the wavelength is reduced to around $320 \mathrm{~nm}$, showing a direct band transition. The absorption edge of the film on $\mathrm{MgO}(\sim 4.75 \mathrm{eV}) \mathrm{ex}-$ tended greatly to the violet side in comparison with that of the bulk KLN crystals. The large shift of the absorption edge to the violet can be attributed to the size effect of the nanostructured film.

Light guiding measurement indicaled that a 2-layer $\mathrm{KLN} / \mathrm{MgO}$ film could support two $\mathrm{T} T \mathrm{~T}$ modes and two TM nodes. The refraclive index of the film is $2.1443 \mathrm{at} 632.8 \mathrm{~nm}$, close to those of KI,N crystal $\left(n_{0}=2.2770, n_{\mathrm{c}}=\right.$ $2.1630 . .^{10}$

In conclusion, we have prepared and characterized sol-grel derived KLN films deposited on $\mathrm{Si}$ and $\mathrm{MgO}$ single crystals. The results have shown that retragonal tungsten-bronze-type KIN films could be obtained with the sol-gel proccss, and highly transparent and oriented KI,N films were successfully deposited on MgO substrates.

1. J.J.F. Reid, "Resonantly enhanced, frequency doubling of an $820 \mathrm{~nm}$ GaAIAs diode laser in a potassium lithium niobate crystal," Appl. Phys, lett. 62, 19 (1993).

2. Y. Furukawa, S. Kakio, T. Miyai, M. Sato, II. Kitayama, Y. Urata, T. T'amiuchi, 'T'. Fukuda, "Growth and characterization of $\mathrm{K}_{3} \mathrm{Li}_{2}\left(\mathrm{la}_{\mathrm{x}} \mathrm{Nb}_{1-\mathrm{x}}\right)_{5} \mathrm{O}_{15}$ crystals for blue second-harmonic-generation applicalions," Appl. Phys. Lett, 68, 744 (1996).

3. Z. Chen, M. Tago, M. Adachi, A. Kawbata, "Growth and properties of tungsten-bronze ferroelectric potassium lithium niobate single crystals," Ferroelectrics 196, 265 (1997)

4. II.R. Xia, I.J. Hu, J.Q. Wei, J.Y. Wang, Y.G. Liu, "Growth and properties of tetragonal tungsten bronze type potassium lithium niobate single crystals," Cryst. Res. \& Tcchnol. 32, 311 (1997).

5. K. Imai, M. Imaeda, S. Uda, T. T'anituchi, 'T. Fukuda, "Homogeneity and SIIG properties of $\mathrm{K}_{3} \mathrm{I}, \mathrm{i}_{2-x} \mathrm{Nb}_{5+x} \mathrm{O}_{15,2 x}$ single crystals grown by micro-pullingdown technique," J. Crystal Growth 177, 79 (1997).
6. M. Ferriol, G. Foulon, $A$. Brenicr, M.T. Cohen-Adad, G. Boulon, "Laser heated pedestal growth of pure and $\mathrm{Nd}^{3+1}$ doped polassium niobate single-crystal fibers," J. Crystal Growth 173, 226 (1997).

7. M. Matsukura, Z. Chen, M. Adachi, A. Kawabala, "Growth of potassium lithitum niobate single-crystal fibers by the laser-heated pedestal growth method," Jpn. J. Appl. Phys. 36, 5947 (1997).

8. G. Loulon, B. Brenier, M. Ferriol, G. Boulon, "Nonlinear laser crystal as a blue converter: laser heated pedestal growth, spectroscopic properties and second harmonic generation of pure and $\mathrm{Nd}^{3-1}$ doped $\mathrm{K}_{3} \mathrm{Li}_{2-\mathrm{x}} \mathrm{Nb}_{r_{-1} \cdot \mathrm{x}} \mathrm{O}_{15+2 \mathrm{x}}$ single crystal filhers," I. Phys. D: Appl. Phys. 29, 3003 (1996).

9. H.R. Xíl, H. Yu, II. Yang, K.X. Wang, B.Y.Zhao, J.Q. Wei, J.Y. Wang, Y. C. Liu, "Raman and infrared reflectivity spectra of potassium lithium niobate single crystals," Phys. Rev. B55, 14892 (1997).

10. V.G. Dmitriev, G.G. Gurzadyan, D.N. Nikogosyan, "Itandbook of Nonlinear Optical Crystals," 229 (Springer-Verlag Berlin ITeidelberg, 1997).

\section{cWK40}

Leakage-free, guidance of light in hollow core optical fibers

S.E. Barkou, J. Broeng, A. Bjarklev, Research Center COM, Technical University of Denmark, Building 348, DK-2800 Lyngby, Denmark; F-mail: seb@com.dtu.dk

Despite their tremendous success optical fibers of today are limited by the laws of total internal reflection. During the past five years, however, it has become increasingly evident, that a new operational principle of optical fibers is possible, namely guidance due to photonic bandgap (PBG) effect. ${ }^{1.3}$

Photonic bandgaps are forbidden photon energy intervals, which may be displayed by periodic dielectric structures (photonic crystals), and correspond to the electronic bandgaps of semiconductor crystals. Such PBGs may exist in periodic silica/air structures. ${ }^{2}$ While it soon became evident that it is possible to guide light in low index core re- gions using these fibers, ${ }^{2-4}$ it was only recently proven that it is possible to guide light almost entirely within an air-core using PIBG fibers, ${ }^{5,6}$ In this presentation we will discuss the theory of such optical fibers and their unique properties.

The transverse design of the analyzed fiber is depicted in the inset of Fig. la,, where air holes are inclicated in black. The central air hole corresponds to the corc of the fiber, while the surrounding periodic air/silica region is the cladding structure. 'The filher is assumed invariant in the longitudinal direction.

In Fig. 1 the normalised frequency, $\mathrm{k} \Lambda$, is shown as a function of the normalised propagation constant, $\beta \Lambda$, where $\Lambda$ is the lattice constant of the periodic cladding structure, $k$ is the wave number and $\beta$ is the propagation constant from standard optical fiber theory. All calculations were performed using a supercell plane-wave method. ${ }^{7}$ The air-filling fraction of the cladding structure in the calculations is $70 \%$. The lowest-frequency mode that is allowed in the cladding structure defines the cladding index of the fibre (eff. index $=\beta / \mathrm{k}$ ). Index-guided modes (as for standard optical fiber) would therefore appear bclow the lowest-frequency cladding mode, in a plot similar to Fig. 1a. No such modes are found for the analyzed fiber. On the other land confined modes are found within the PBGs exhibited by the cladding structure as illustrated by the second inset in Firg. 1a. This indicates that it is possible to have guided modes with a modeindex below the effective index of the cladding. The PBG regions to the left of the air-line in liig. 1a even have a wavenumber larger than the propagation constant. It is thereforc theoretically possible to obtain guided modes with all their energy in air.

I'wo localised modes are found for the analyzed fiber: a fundamental mode and a second order mode. Both modes are within the PBG for some frequencies, and outside the PBG for other frequencies. The modal ficld distribution for the fundamental mode is shown in Fig. $1 b$, for $k \Lambda=9.0$ where the mode is within the PBG in Fig. 1a. It is noticed that it is indeed possible to guided light in air regions. However, when the mode cxits the $P B G$ in Fig. 1a two things happen: 'l'he mode enters a region where it may conple to cladding modes. This tendency for the mode to become leaky is further on-
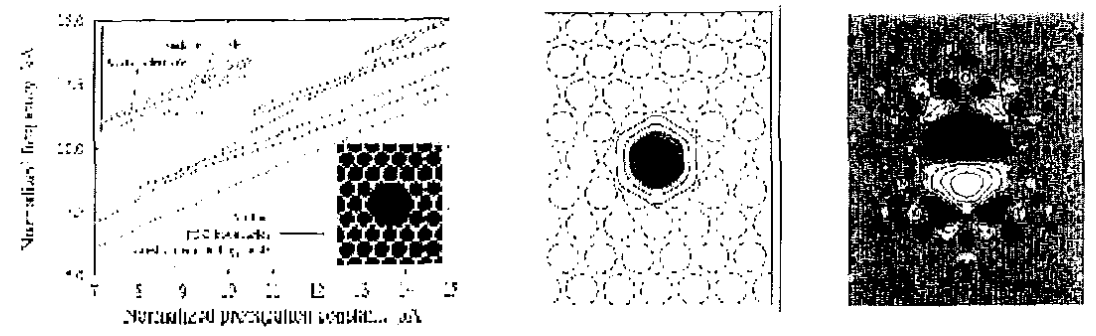

CWK40 liig. 1. (a) The optical fiber structure investigated (inset). A large hollow core is introduced in the central part of the fiber. The light may be guided in this region duc to the periodic silica/air claclding structurc. Then the guide mode lies within a photonic bandgap bandgap of the cladding structure. (b) Modal ficld distribution of the fundamental guided mode. It is well localised to the hollow core. Further the mode is within a PBG of Fig. la and is therefore strictly guided, (c) Modal field distribution of the second order guided mode. The mode is not within a PBG and is therefore leaky. A significant amount of the field is in the cladding region. 
hanced, since the localised fundamental mode becomes less confined: an increasingly portion of the ficld is outside the hollow core as the frequency moves away from the P'BCr. 'This tendency is illustrated for the second order guided mode in Fig. $1 \mathrm{c}$, which is depicted for a frequency where the guided mode is not within the PB (r: 'The mode is not as localised to the lollow core, and is furthermore leaky.

As a conseguence of the limited extent of the l'l3Gis, the guided modes of PBC $\mathrm{P}$ fibers will always act as bandpass filters. Irowever, fibers where the localised modes act as the modes described above, will have a novel quality: 'the width and slope of the filter will depend on the actual length of the fiber. llowever, it should be noticed that fibers which guide light at wavelengths which are farr shorter than the lattice constant of the cladding structure will typically have narrow bandgaps, and are therefore likely to have very natrow spectral ranges, where gyidance is leakage frec. This would therefore put severe restraints on the homogenily necessary in the final optical fiber. 'The fiber calculated upon here has a leakage free window in the order of $40 \mathrm{~mm}$, when guidance is in the $1550 \mathrm{~nm}$ tange.

In conclusion we have shown that it is possible to gtide light leakage-free in air, in narrow spectral ranges. The analyzed fiber is not strictly single-mode, however, this may be remedied by using a fiber with a smaller air corc. The importance of hollow core fibers is that they may be al most dispersionless and very linear. Furthermore, it is possible to use these fibers in sensoring schemes, or to introduce non linear gasses into the airholes to obtain new non lincar fibers. This list is far from exhaustive: Possibly most importantthe possibilities with these fibers are so novel, that any list will probably be far from exhalustive.

'This work was supported by the 1)anish Technical Research Council under the 'IHOR ('l'cchnology by Ilighly Oricnted Research) program.

I. 'T.A. Birks, P.J. Roberts, P.St.J. Russell, D.M. Atkit, 'IJ.J. Shepherd, lilectronics I.ctters, 31,(22) 1941.3, ()ct. 1995.

2. S.li. Barkou, J. Broeng, A. Bjarklev. Optics Letters, 21(19) 1547-9, Jan 1999.

3. J.C. Knight, J. Broeng, 'l. $\Lambda$. Birks, and P.St.J. Russcll. Science, vol. 282, No. 5393, $1476-1478,1998$.

4. J. Broeng, S.I. Barkou, $\Lambda$. Bjarklev, J.C. Knight, 'I'A. 13irks, P.St.J. Russell. Optics Communications, 156,(4-6) 240-4, Nov, 1998.

5. R.I. Cregan, B.J. Mangan, J.C. Knight, 'T.A. Kuight, T'A. Birks, P.St.J. Russell, P.J. Roberts, D.C. Allan, Science 285, 1537 (1999).

6. J. Brocng, S.J. Barkou, T. Søndergatard, A. Bjarklev, "Analysis of air-guiding photonic band gap fibers", Optics 1.etters, In Press.

7. R.J. Meade, A.M. Rappe, K.I). Brommer; J.1). Joannopuolos, O.L. Alcrlatnd, Phys. Rev. B., 48, 8834-7, 1993.

\section{CWK41}

Long distance measurement with high spatial resolution by optical frequency domain reflectometry using a frequencyshifted feedback fiber laser

M. Yoshida, K. Nakmuta, Hiromisa Ito, Research Instinute of Elettrical Comm, Tohoka Univ. Sendai, 980-8577, Japan; L-mail: masato@riec.tohoku.ac.jp

Optical ranging is innortant in various ficlds, such as the chillacterization of an optical network, fiber optic sensors, and so on. "lo implement these applications, a spatial resolution better thau $1 \mathrm{~cm}$ over an operating range of tens of kilometers is clesirable. Such performance, however, has not yet been demon. strated, as far as we know. In this paper we demonstrate long distance neasurement by atl optical frequency domain reflectometry (OIDR) using al frequency-shifted feedback (IS]) fiber laser, and achieve a spatial resolu. tion of $0.4 \mathrm{~cm}$ at an operating range of $20 \mathrm{~km}$.

l'igure 1 shows the experimental of'loR setup with the FSl fiber laser using an erbiumdoped fiber as the gain medium. In this experiment, the path difference of the Michelson interferometer was set $1059 \mathrm{~km}$, using $20 . \mathrm{km}$ dispersion shifted fiber (DSF) and single node fiber (SMH) als test fibers to investigate the performance of long distance measurement. Fig. 2 shows the beat spectra of a self-dclayed heterodyne signal for the (a) I)SL' and (b) SML: test fibers. Since the lisli lascr output consists of a chirped frequency comb, the beat frequency is given by

$$
f_{B m}=\frac{V_{R S} Z}{\tau_{R T}<}-\frac{m}{\tau_{R T}}
$$

or

$$
z={ }_{y_{l: S}}^{c}\left(\tau_{k W{ }_{m}}+m\right)
$$

where $v_{i s}$ is the frequency shift per round trip $(=110 \mathrm{MI} / z), 1 / \tau_{R T}$ is the cavity FSR $(7.85$ MIL $\%$ ), $z$ is the path difference of the interferometer, and $m$ is the "beat order". The beat order $m$ is determined by the slope of the $m-\mathrm{th}$ order beat frequency $\int_{P_{m}}$ plotted against the

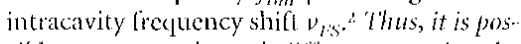
sible to measure the path difference, $z$, using the

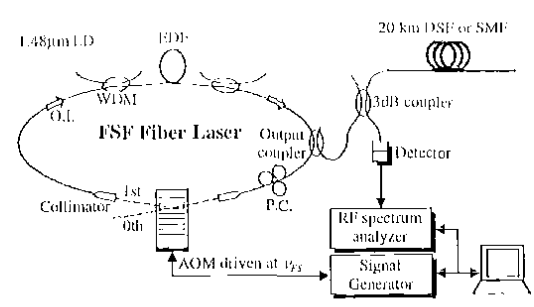

CWK41 lige. 1. The experimental setup for long distance measurement using an liSF fiber laser, liDl: erbium doped fiber, WIOM: wavelength division multiplexing coupler, PC: polarizaltion controller, $A(\mathrm{M}$ : acousto-optic nodulator. 'The driving frequency of the $\Lambda$ OM wils 110 $\mathrm{MHz}$, the cavity l'SR was $7.85 \mathrm{Mr} \%$, the output wavelengl h was $1.557 \mu \mathrm{m}$, and the frequencychirp range was 100 (if l $\%$.
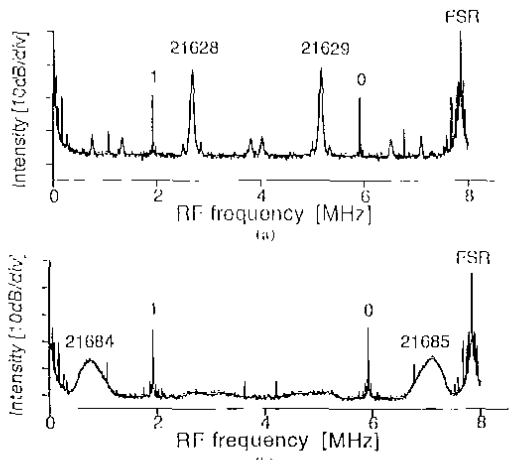

(b)

CWK41 Fig. 2. Beat spectrum of the selfdelayed heterodyne signal for $z=59 \mathrm{knn}$. (a) ISSt: and (b) SMF were used as test filers. 'lhe lower $\left(0^{1 \mathrm{th}}\right.$ and $\left.1^{\mathrm{st}}\right)$ and higher $\left(>20,000^{\mathrm{th}}\right)$ order beat signals corresponded to the signals reffected from the two connectors of the test fiber.

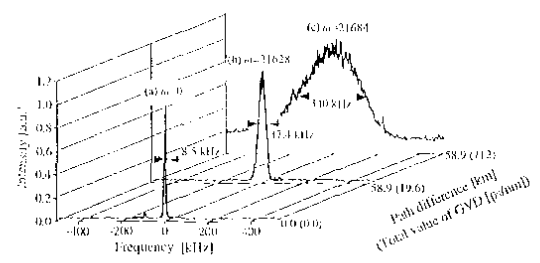

CWK4J Fig. 3. Beal spectra of the (a) $0^{11}$ and higher order beal signtals for both the (b) I)SY and (c) SMI cases shown in lizs. 2. The spectrum widths (IFWI-IM) were $8.5 \mathrm{kTL} \%, 37.4 \mathrm{kI} \mathrm{L} \%$, and 340 $\mathrm{kI} I z$, respectively,

higher order beal frepuency observed within the cavity lisk for any path difference.

In Fig. 2 the lowes $\left(0^{\text {th }}\right.$ and $\left.1^{\mathrm{si}}\right)$ and higher $\left(>20,000^{\text {th }}\right)$ beat signals corresponded to the signals reflected from the two connectors in the test fiber. Hig. 3 shows the entaryed beat spectra of the (a) $0^{\text {th }}$ and higher order beat signals for both the (b) I)SE $\left(21,628^{\mathrm{th}_{1}}\right)$ and (c) SMI: $\left(21,684^{\text {th }}\right)$ cases shown in ligg. 2. The spectrum widtlis (I'WHM) of the beat signals were (a) $8.5 \mathrm{kr} \mathrm{L} \%$ (b) $37.4 \mathrm{kII} \%$, and (c) 340 $\mathrm{kl} \mathrm{l} \%$, respectively. The corresponding spatial resolutions were calculated to be $0.1 \mathrm{~cm}, 0.1$ $\mathrm{cm}$, and $3.9 \mathrm{~cm}$ using $\mathrm{Eq}$. (1). The spectrum width of the $0^{\text {th }}$ order beat signal is determined by the frequency chirp range of the light source (-100 (ill\%), and limits the spatial resolution of this taser. 'the broadening of the spectrum width of the higher order beat signals is caused mainly by the effect of the (FVD) of the test fiber. ${ }^{3}$ This indicates the importance of tuning the wavelengll of the light source to the zero dispersion wavelength of the test fiber for a long distatice measurement. When the ISSF was used as the test fiber, the pall difference $z$ was measured as $58.986382 \mathrm{~km}$ from the fact that the $21.628^{\text {th }}$ beat fiecpuency $f_{3 m}$ was 2.67 MHz.. The ratio of the spatial resolution to the operating range $\Delta z / z$ was $2 \times 10^{\circ}$, which is the best result to date for optical ranging, as fac as we know.

In conclusion, we report the first Olid) (lemonstration of the use of al lisli fiber laser to achieve a spatial resolution of better than $1 \mathrm{~cm}$ over an operalting range of tens of kilometers. 